\title{
O ATENDIMENTO ÀS DCNS DE 2019 EM UMA DISCIPLINA DURANTE A PANDEMIA DE 2020
}

Osvaldo S.Nakao-nakao@usp.br

USP, Escola Politécnica, Departamento de Engenharia de Estruturas e Geotécnica

Av. Prof. Almeida Prado, travessa do Biênio (antiga trav. 2), 83

CEP 05580-200 - São Paulo - SP

José A. Baesso Grimoni-aquiles@pea.usp.br

USP, Escola Politécnica, Departamento de Engenharia de Energia e Automação Elétrica Av. Prof. Luciano Gualberto, travessa do Politécnico (antiga trav. 3), 158

CEP 05508-900 - São Paulo - SP

Resumo: Com a publicação das Diretrizes Curriculares de Engenharia em 2019, as competências a serem desenvolvidas nos alunos dos cursos de graduação em engenharia ficaram bem explícitas. Por intermédio de um projeto de engenharia proposto aos alunos do $1^{\circ}$ semestre letivo aplicou-se a aprendizagem ativa com muito sucesso na disciplina 0313101 Introdução à Engenharia Civil da Escola Politécnica da USP. Ela está adequada para desenvolver os conhecimentos, as habilidades $e$ as atitudes apontadas conforme a enquete aplicada ao final do $1^{o}$ semestre de 2020, mesmo com todas as dificuldades ocorridas em função do isolamento social imposto pela propagação do Corona vírus no Brasil.

Palavras-chave: Diretrizes curriculares. Aprendizagem ativa. Introdução à engenharia. Avaliação.

\section{INTRODUÇÃO}

As Diretrizes Curriculares Nacionais do Curso de Graduação em Engenharia (DCNs), que devem ser observadas pelas Instituições de Educação Superior (IES) na organização, no desenvolvimento e na avaliação do curso de engenharia no âmbito dos Sistemas de Educação Superior do país, foram publicadas no DOU em 23 de abril de 2019 de acordo com o parecer $\mathrm{CNE} / \mathrm{CES} \mathrm{n}^{0} 1 / 2019$.

$\mathrm{Na}$ verdade, as DCNs traduzem o movimento que já se observava em função da realidade das gerações que chegaram ao curso superior neste milênio e modificam os modelos mais tradicionais de aprendizagem.

Assim, as atividades a serem desenvolvidas durante o curso devem ter como foco o perfil do egresso do curso de graduação em Engenharia que é definido pelo artigo $3^{\circ}$ da Resolução que instituiu as DCNs:

I - ter visão holística e humanista, ser crítico, reflexivo, criativo, cooperativo e ético e com forte formação técnica;

II - estar apto a pesquisar, desenvolver, adaptar e utilizar novas tecnologias, com atuação inovadora e empreendedora;

III - ser capaz de reconhecer as necessidades dos usuários, formular, analisar e resolver, de forma criativa, os problemas de Engenharia; 
IV - adotar perspectivas multidisciplinares e transdisciplinares em sua prática;

V - considerar os aspectos globais, políticos, econômicos, sociais, ambientais, culturais e de segurança e saúde no trabalho;

VI - atuar com isenção e comprometimento com a responsabilidade social e com o desenvolvimento sustentável.

Na disciplina 03133101 Introdução à Engenharia Civil, ministrada aos cerca de cento e trinta alunos ingressantes na habilitação Engenharia Civil da Escola Politécnica da USP (EPUSP), sucessora da disciplina PNV 2100 Introdução à Engenharia implementada em 1999 (NAKAO et al., 2011), já havia a preocupação em desenvolver esse perfil agora explicitado pelas DCNs.

A metodologia adotada na disciplina foi PBL (Problem Based Learning), que consiste no aprendizado baseado na resolução de problemas e, segundo Giannotti et al. (2008), é visto como uma abordagem para educar, tanto pelo conteúdo programático constante dos currículos quanto pelo processo, pelo qual problemas são cuidadosamente selecionados e desenvolvidos, demandando a aquisição de conhecimento crítico, proficiência em resolver problemas, estratégias de autoaprendizado e habilidade para trabalhar em grupo. Os problemas propostos procuram reproduzir a abordagem de casos reais, ajudando a enfrentar desafios que podem ser encontrados na vida profissional. O PBL é uma estratégia pedagógica para contextualizar situações do mundo real, provendo recursos e base para o desenvolvimento de conteúdos e habilidades para solução de problemas (SAVERY; DUFFY, 1996).

À medida que a disciplina foi sendo oferecida, houve um aprimoramento de modo que se pode enquadrar a estratégia aplicada atualmente como aprendizagem ativa (ELMOR-FILHO et al., 2019). A aprendizagem ativa pode ser descrita como constituída por três eixos estruturantes, a experiência colaborativa, o conteúdo online e o ensino diferenciado. Desse modo, o aluno desempenha um papel de protagonista no processo de aprendizagem, tendo uma maior autonomia na busca pelo conhecimento, pelo desenvolvimento de habilidades e pelo fortalecimento das atitudes que definem a competência, de acordo com Nakao et al. (2012).

O conteúdo online permite que se vá além da sala de aula e amplie as experiências pela disponibilização de textos, vídeos e filmes. A reprodução da filmagem de uma obra ou serviço de engenharia especial ou de uma construção de ponte de forma acelerada trazem ao estudante de engenharia civil um conhecimento que só seria alcançado após muitos anos de experiência e vivência na vida real.

O ensino diferenciado é um aspecto importante para o processo de aprendizagem. Podendo permitir que o acompanhamento das aulas seja, por exemplo, assíncrono, pois a disponibilização de aulas gravadas possibilita maior flexibilidade para o ato de assistir às aulas e para o reforço do conteúdo visto presencialmente.

\section{AS ATIVIDADES}

No planejamento da disciplina, definiu-se que ela deveria propiciar que o aluno entendesse o que é a Engenharia, sobretudo no que se refere a identificar necessidades que impliquem em ações da Engenharia em enunciar problemas, em formular alternativas de solução, em escolher e em especificar uma solução.

Os cursos de graduação em Engenharia têm nos dois primeiros anos letivos as disciplinas ditas "básicas". Física e Cálculo, que por serem muito teóricas e abstratas, são apontados como responsáveis pelo desencanto dos estudantes com a carreira e pela grande evasão nesse período. Assim, para superar essa dificuldade, na disciplina 0313101, mesmo sendo no primeiro 
semestre letivo do curso, vivenciou-se um trabalho de engenheiro, como membros de uma equipe, buscando informações e produzindo conhecimento em parceria com colegas e professores e encontrando soluções para alguns dos problemas identificados pelos próprios estudantes.

Os alunos ingressantes em Engenharia Civil, em 2020, matriculados em 0313101, foram divididos em 3 turmas e os professores dessas turmas dividiram seus cerca de 40 alunos em oito grupos, numerados de 1 a 8, com aproximadamente cinco alunos em cada um.

Em 2020, o tema escolhido para o desenvolvimento do projeto de engenharia foi "Aprimoramento dos espaços do prédio da engenharia civil" que incluía os quatro subtemas (ambientes): salas de aula; espaço de estudo e biblioteca; restaurante; área de convívio e descanso.

A escolha do tema considerou a motivação que os alunos têm quando o problema a ser investigado é de grande interesse deles próprios (TOLEDO et al., 2019).

O projeto temático foi dividido em duas fases e, em cada uma delas, os oito grupos trabalharam apenas nos quatro ambientes do tema relativos à etapa, e cada ambiente foi tratado por dois grupos chamados de espelhos que, ao final da fase, competiram entre si. Assim, na primeira fase do projeto, cada dois grupos identificaram as necessidades e definiram problemas ou das salas de aula (grupos 1 e 5), ou da biblioteca (grupos 2 e 6), ou dos espaços de convívio e descanso (grupos 3 e 7), ou do restaurante (grupos 4 e 8).

A partir do diagnóstico, pesquisaram alternativas de solução, relatando o que foi realizado em um relatório entregue ao final dessa fase (na quinta semana) que foi corrigido pelo professor. Para finalizar a fase, houve também uma competição entre o grupo e o grupo espelho que consistiu na apresentação do trabalho de cada grupo para a turma. Os demais grupos votaram no grupo que fez o trabalho mais completo, por meio de uma cédula de votação, em que existem sete perguntas para que a reflexão permita a escolha justa, quais sejam: Qual dos grupos-espelho fez uma exposição mais clara? Qual dos grupos-espelho fez uma síntese mais bem elaborada? Qual dos grupos elaborou uma melhor contextualização do tema? Qual dos grupos-espelho efetuou um melhor trabalho de levantamento de dados? Qual dos grupos-espelho efetuou uma melhor análise de dados? Qual dos grupos-espelho elaborou uma melhor definição do problema? Qual dos grupos-espelho elaborou maior diversidade de alternativas (inovadoras e convencionais)?

$\mathrm{Na}$ segunda fase do projeto, desfizeram-se os grupos da primeira fase e houve a formação de novos grupos com cerca de cinco alunos, mantendo-se pelo menos dois alunos do grupo da primeira fase. Na segunda fase, a exemplo da anterior, os grupos foram formados pelo professor para evitar as denominadas "panelas", e, assim, propiciar a cada aluno se relacionar com outras pessoas, mesmo que desconhecidas, como é o cenário que se encontra no mundo real. Essa reorganização dos grupos procurou preparar os futuros engenheiros para as situações em que, muitas vezes depois de interrupções nos projetos, outros devem prosseguir corrigindo ou complementando o que foi feito na primeira etapa.

Nesta segunda fase, houve o estabelecimento de critérios para a escolha das soluções, porque sempre há conflito entre elas e muitas vezes é difícil escolher uma delas. Por vezes a solução que atende a um critério não atende a um outro. Para essa escolha e avaliação de soluções, apresentaram-se alguns métodos utilizados na Engenharia, conhecidos como matrizes de decisão. O Método de Análise Hierárquica - Analytic Hierarchy Process (AHP) foi um desses métodos. Escolhida uma solução, especificou-se essa solução da melhor forma, lembrando que como são alunos de primeiro ano, nem sempre os conhecimentos permitiram fazer as especificações de forma completa. 
Para finalizar essa fase, na nona aula, houve também uma competição entre o grupo e o grupo espelho que consistiu na apresentação do trabalho elaborado a partir do conjunto de soluções encontradas na primeira fase. Os demais grupos votaram em qual dos dois grupos fez o trabalho mais completo, levando em conta aquelas mesmas perguntas que acompanharam a votação na primeira competição intergrupos.

Houve sempre a preocupação dos professores em esclarecer as razões e os porquês dos procedimentos adotados, desde o primeiro contato na disciplina, estabelecendo o que se convencionou chamar de contrato pedagógico. Isso se fez necessário, porque a forma de avaliação adotada com a opinião dos pares não é confortável para alguns dos alunos que, na idade em que se encontram, são muito críticos em relação aos outros e a eles mesmos.

Mudou-se, assim, o paradigma do processo de ensino e aprendizagem, que passou a enfatizar mais o aprender do que o ensinar. Como aprender é buscar informações, rever a própria experiência, adquirir habilidades, adaptar-se às mudanças, descobrir significados nos fatos, modificar atitudes e comportamentos, as atividades foram centradas no aluno (MASETTO et al., 2017). Assim, além de questionar o que era importante ensinar e como fazêlo, procurou-se estabelecer uma avaliação que também fosse realizada com intensa participação dos alunos. Como o estudante, tanto no ensino fundamental como no ensino médio, convive e se acostuma com as avaliações traduzidas em menções e notas, criou-se um algoritmo que aproveitou da motivação extrínseca, representada pela nota nesse processo para trazer mais benefícios e favorecer a motivação intrínseca.

\section{A AVALIAÇÃO}

$\mathrm{O}$ algoritmo que deu a nota final (NF) e que procurou incorporar uma boa parte dos objetivos da disciplina é a fórmula:

$$
N F=10 x\left(f_{g}+p\right) x f_{p}
$$

Em que $f_{g}$ é o fator de grupo, $p$ é o prêmio e $f p$ é o fator de participação.

$\mathrm{O}$ fator de grupo $f_{g}$ foi obtido pela média aritmética dos dois fatores de grupo obtidos por cada aluno, como membro de dois diferentes grupos, em cada uma das duas competições, ao final de cada fase do projeto. Nessas competições, o grupo que se saiu melhor, na opinião dos outros alunos da turma, recebeu 1,0, e o outro, 0,9. No final do semestre, cada aluno teve duas pontuações de grupo correspondentes a cada uma das fases do projeto. Cada aluno teve, como fator de grupo: 1,0, se pertenceu a grupos ganhadores nas duas fases; 0,95, se fez parte de um vencedor e de um perdedor; 0,9 se esteve em dois grupos que perderam as competições.

O fator de participação $f_{p}$ foi obtido por:

$$
f_{p}=\left(f_{p p 1}+f_{p p 2}\right) / 2 \times f_{S 12} \times f_{I}
$$

O fator de participação individual $f_{p p}$ na fase 1 e na fase 2 foi o fator que o grupo distribuiu a cada um de seus membros a partir da nota (um valor entre 0 e 1,0) do relatório do projeto atribuído pelo docente.

Na EPUSP, a meritocracia considerada na distribuição de bolsas ou no julgamento para a concessão de vagas para os programas de inserção aos intercâmbios internacionais é baseada nas médias das disciplinas. Para não haver discrepâncias, as notas atribuídas pelos docentes da disciplina nas três turmas precisavam ter uma distribuição (desvio padrão) igual para que o 
critério de um dos professores não fosse diferente dos demais. Para isso, a média das notas dos três professores nos relatórios da turma foi pré-fixada em 0,75 . Depois de o professor atribuir um valor até 1,0 ao relatório do grupo, os membros do grupo se atribuíram $f_{p p 1}$ e $f_{p p 2}$ em cada etapa do projeto temático, tal que a média das pontuações em um grupo fosse igual à pontuação dada pelo professor. Pode ter ocorrido que, num grupo de cinco alunos, se a pontuação dada pelo professor foi 0,8 , o valor atribuído foi 1,0 para três dos alunos, 0,6 para o quarto membro e 0,4 para o quinto membro em função da dedicação de cada membro do grupo. Essa decisão, com relação à divisão das notas, foi consensual e acordada por todos do grupo.

Além dessas duas competições entre os grupos e os grupos-espelhos da mesma turma, houve uma terceira competição entre o "grupão" formado por todos os grupos 1, 2, 3 e 4 e o "grupão-espelho" formado pelos grupos-espelho 5, 6, 7 e 8. Observe que com isso, todos os ambientes ficaram representados nos dois "grupões". Portanto, nessa última competição apresentou-se o projeto global incluindo todos os ambientes e a avaliação foi feita por um conjunto de professores convidados que puderam atribuir 1,0 para os "grupões" ou 1,0 para o melhor ou 0,9 para o outro como o fator $f_{12}$.

O fator $f_{I}$ foi o resultado da aplicação de uma prova escrita aplicada na semana de provas, segundo o calendário da Coordenação do Ciclo Básico, que distribuiu as provas das disciplinas em determinados períodos. Constituiu-se em uma avaliação dos conceitos sobre o método de projeto e o projeto desenvolvido e, para o cálculo, as notas da prova foram distribuídas em 3 faixas. Nas notas acima de 7,0, adotou-se o fator $f_{I}$ igual a 1,0; nas notas entre 5,0 e 7,0, adotouse o fator $f_{I}$ igual a 0,9 ; nas notas abaixo de 5,0 , adotou-se 0,8 .

O desenvolvimento do projeto pela turma foi uma simulação do que se faz em um escritório de Engenharia. Portanto, apesar da competição interna à turma (que, em algumas situações, ocorre nas empresas, entre os grupos), o conjunto, como turma, foi preservado e, ao final do semestre, houve a oportunidade de os alunos de cada turma atribuírem um prêmio àqueles mais empenhados. A pontuação do prêmio $p$ foi decidida pela turma que atribuiu 0,1 a quatro alunos (10\% da turma), 0,07 a oito alunos (20\% da turma) e 0,03 a oito alunos (20\% da turma). Quando os alunos da turma não conseguem decidir quais os colegas que devem receber o prêmio, esse prêmio não é atribuído. Em anos anteriores, essa dificuldade foi sentida em algumas turmas demonstrando claramente a necessidade desse exercício para desenvolver a habilidade de autoavaliar e negociar.

\section{A PANDEMIA}

Ao se efetuar o planejamento de uma disciplina para um curso de Engenharia não se poderia sequer imaginar os cenários que ocorreram neste primeiro semestre de 2020. Com a propagação da infecção pelo SARSCoV-2 (novo coronavírus), foi imposto um isolamento social, que obrigou as instituições de ensino a suspender suas atividades presenciais. fazendo com que muita coisa fosse alterada.

No campus da Capital, na Cidade Universitária, o acesso dos alunos da EPUSP foi interrompido no dia 23 de março de 2020. Dessa forma, na referida disciplina, houve apenas duas aulas presenciais. Com o tema do projeto (Aprimoramento dos espaços do prédio da Engenharia Civil) divulgado na segunda aula, essa proibição prejudicou o objetivo que era detectar pontos positivos e negativos nos espaços e propor soluções para patologias e melhorias nas condições de conforto e eficiência por meio de projetos com a vertente de sustentabilidade.

Todos os atores envolvidos, desde o reitor da USP, a diretora da escola, os coordenadores de cursos, os responsáveis pelas disciplinas, os docentes e os estudantes se preocuparam com o 
processo de ensino e aprendizagem, mas para evitar um prejuízo maior, aceitaram as necessárias adaptações nas estratégias do processo de ensino e aprendizagem com a adoção de tecnologias digitais. A diretoria da EPUSP e os centros acadêmicos se preocuparam em disponibilizar meios para que todos os alunos pudessem acompanhar as aulas remotamente.

Assim, a partir da terceira, as aulas foram dadas utilizando-se o Google Meet e os alunos precisaram usar a criatividade para o desenvolvimento do projeto, mesmo impedidos de efetuar as visitas técnicas presenciais. Embora os ambientes a serem estudados fizessem parte da realidade do ingressante do curso de engenharia civil da EPUSP, eles só vivenciaram esses ambientes durante três semanas, incluindo a semana de recepção, e de fato não conseguiram ter uma noção mais acurada.

A estratégia aplicada pelos grupos foi consultar os alunos que frequentavam o prédio há mais tempo. Assim, fez-se o contato com os alunos do $2^{\circ}, 3^{\circ}, 4^{\circ}$ e $5^{\circ}$ anos e os professores, utilizando a internet e consultando as mídias sociais. A coleta dos dados foi feita a partir de questionários, respondidos pelos que se dispuseram, identificando a percepção nos diversos aspectos, avaliando os pontos fortes e fracos para uma melhoria contínua dos ambientes e a perspectiva da possível adoção de algumas soluções após o isolamento social.

\section{AS COMPETENCIAS DEFINIDAS PELAS DCNS QUE FORAM DESENVOLVIDAS}

A seguir, após a descrição de cada competência definida pelas DCNs, há um resumo do que foi desenvolvido na disciplina para despertar o que se espera do egresso.

A primeira competência listada no Art. $4^{\circ}$ é formular e conceber soluções desejáveis de engenharia, analisando e compreendendo os usuários dessas soluções e seu contexto: a) ser capaz de utilizar técnicas adequadas de observação, compreensão, registro e análise das necessidades dos usuários e de seus contextos sociais, culturais, legais, ambientais e econômicos; b) formular, de maneira ampla e sistêmica, questões de engenharia, considerando o usuário e seu contexto, concebendo soluções criativas, bem como o uso de técnicas adequadas.

Nos anos anteriores os temas escolhidos para o projeto foram provocativos e formativos do cidadão. Foram tratados o uso racional da água em um edifício comercial; a racionalização da energia elétrica em um edifício; a mobilidade urbana na cidade de São Paulo; a revitalização do riacho do Ipiranga, temas que remetiam ao conhecimento de macro políticas. Neste ano, com a escolha do tema voltado no ambiente do cotidiano dos alunos, embora a formação da cidadania seja sempre objeto de preocupação dos professores, a capacitação foi voltada principalmente para a técnica da Avaliação Pós Ocupação (APO) que foi apresentada na terceira aula e permitiu o diagnóstico e registro das principais necessidades dos usuários e orientou a concepção de soluções criativas.

A segunda competência listada no Art. $4^{\circ}$ é analisar e compreender os fenômenos físicos e químicos por meio de modelos simbólicos, físicos e outros, verificados e validados por experimentação: a) ser capaz de modelar os fenômenos, os sistemas físicos e químicos, utilizando as ferramentas matemáticas, estatísticas, computacionais e de simulação, entre outras. b) prever os resultados dos sistemas por meio dos modelos; c) conceber experimentos que gerem resultados reais para o comportamento dos fenômenos e sistemas em estudo; d) verificar e validar os modelos por meio de técnicas adequadas.

$\mathrm{Na}$ fase de concepção de soluções, os alunos precisaram conceber modelos e fazer estudos de sua eficiência de forma comparativa nas matrizes de decisão por meio da técnica AHP, 
conforme já foi relatado. Alguns dos alunos conseguiram recorrer ao conhecimento da Física das construções, embora não tenham podido utilizar os instrumentos existentes para medir os lúmens e os decibéis.

A terceira competência listada no Art. $4^{\circ}$ é conceber, projetar e analisar sistemas, produtos (bens e serviços), componentes ou processos: a) ser capaz de conceber e projetar soluções criativas, desejáveis e viáveis, técnica e economicamente, nos contextos em que serão aplicadas; b) projetar e determinar os parâmetros construtivos e operacionais para as soluções de Engenharia; c) aplicar conceitos de gestão para planejar, supervisionar, elaborar e coordenar projetos e serviços de Engenharia.

Disponibilizaram-se vários vídeos com soluções contemporâneas e modernas para estimular e despertar a criatividade, tanto no site da disciplina como em um site criado para divulgar a engenharia civil da EPUSP (engcivilpoliusp.net).

A quarta competência, listada no Art. $4^{\circ}$, é implantar, supervisionar e controlar as soluções de Engenharia: a) ser capaz de aplicar os conceitos de gestão para planejar, supervisionar, elaborar e coordenar a implantação das soluções de Engenharia; b) estar apto a gerir, tanto a força de trabalho quanto os recursos físicos, no que diz respeito aos materiais e à informação; c) desenvolver sensibilidade global nas organizações; d) projetar e desenvolver novas estruturas empreendedoras e soluções inovadoras para os problemas; e) realizar a avaliação críticoreflexiva dos impactos das soluções de Engenharia nos contextos social, legal, econômico e ambiental.

O estudante precisou conceber, projetar e analisar as soluções para o aprimoramento dos espaços do prédio. Nos grupos em que se elaborou o projeto em equipe, aprendeu a supervisionar ou coordenar ou participar com responsabilidade do projeto que era o objetivo comum. Na elaboração da matriz de decisão no processo AHP, realizou-se uma avaliação crítico-reflexiva dos impactos das soluções.

A quinta competência listada no Art. $4^{\circ}$ é comunicar-se eficazmente nas formas escrita, oral e gráfica: a) ser capaz de expressar-se adequadamente, seja na língua pátria ou em idioma diferente do Português, inclusive por meio do uso consistente das tecnologias digitais de informação e comunicação (TDICs), mantendo-se sempre atualizado em termos de métodos e tecnologias disponíveis.

$\mathrm{Na}$ entrega dos dois relatórios dos grupos e na formulação do relatório do "grupão", os estudantes puderam aprender a formatação de um relatório de engenharia, de acordo com a ABNT. Para facilitar esse primeiro contato com a escrita técnica, foi disponibilizado um template e liberado acesso às normas oficiais por meio de um convênio que a USP mantém. Paralelamente à entrega dos relatórios, os alunos fizeram três apresentações utilizando o Power Point para que os colegas pudessem opinar qual era o melhor trabalho de acordo com as perguntas já relatadas. Neste ano, com o isolamento social, superaram-se muitos obstáculos como as dificuldades de ligação pela internet, ou as participações simultâneas de vários alunos em uma mesma apresentação.

A sexta competência listada no Art. $4^{\circ}$ é trabalhar e liderar equipes multidisciplinares: a) ser capaz de interagir com as diferentes culturas, mediante o trabalho em equipes presenciais ou a distância, de modo que facilite a construção coletiva; b) atuar, de forma colaborativa, ética e profissional em equipes multidisciplinares, tanto localmente quanto em rede; c) gerenciar projetos e liderar, de forma proativa e colaborativa, definindo as estratégias e construindo o consenso nos grupos; d) reconhecer e conviver com as diferenças socioculturais nos mais diversos níveis em todos os contextos em que atua (globais/locais); e) preparar-se para liderar empreendimentos em todos os seus aspectos de produção, de finanças, de pessoal e de mercado. 
O trabalho desenvolvido com o projeto é em equipe e, com isso, desenvolveram-se as lideranças e as responsabilidades. Houve oportunidades para que se corrigissem ou fortalecessem vários aspectos dos liderados e das lideranças como o domínio da escrita e da oratória. Tanto na distribuição das notas de participação como na atribuição dos prêmios aos que se destacaram, foram construídas as competências necessárias para os trabalhos em equipe e para o autoconhecimento. Além disso, a pandemia proporcionou a capacitação para o trabalho em equipe à distância.

A sétima competência listada no Art. $4^{\circ}$ é conhecer e aplicar com ética a legislação e os atos normativos no âmbito do exercício da profissão: a) ser capaz de compreender a legislação, a ética e a responsabilidade profissional e avaliar os impactos das atividades de Engenharia na sociedade e no meio ambiente; b) atuar sempre respeitando a legislação, e com ética em todas as atividades, zelando para que isto ocorra também no contexto em que estiver atuando.

No site da disciplina, são disponibilizados vários textos como o Projeto Pedagógico do Curso de Engenharia Civil, as Diretrizes Curriculares do Curso de Engenharia Civil, Resoluções do Conselho Regional de Engenharia e Agronomia (CREA) e do Conselho Federal de Engenharia e Agronomia (Confea) antecipando a legislação que regula a profissão e a formação esperada ao final do curso de graduação.

A oitava competência listada no Art. $4^{\circ}$ é aprender de forma autônoma e lidar com situações e contextos complexos, atualizando-se em relação aos avanços da ciência, da tecnologia e aos desafios da inovação: a) ser capaz de assumir atitude investigativa e autônoma, com vistas à aprendizagem contínua, à produção de novos conhecimentos e ao desenvolvimento de novas tecnologias; b) aprender a aprender.

Pode-se concluir que os alunos puderam assumir, de forma proativa, uma atitude de aprender a aprender pelo fato de desenvolverem este projeto a partir das explicações gerais dos professores e da disponibilização de vídeos com as práticas modernas da engenharia civil que permitiram a atualização com o estado da arte.

\section{OPINIÃO DOS ALUNOS SOBRE A DISCIPLINA}

No final do semestre, foi disponibilizada uma enquete no site (plataforma Moodle) para que os alunos manifestassem, de forma livre e anônima, a opinião sobre o desenvolvimento da disciplina. Todas as questões foram propostas para que fosse assinalada uma alternativa entre cinco, que evoluíam de muito ruim a muito bom.

Atenderam ao convite $63 \%$ dos que concluíram a disciplina.

Dentre eles, com relação ao entendimento da Engenharia, assinalaram bom ou muito bom, quanto a identificar problemas, $90 \%$; quanto a enunciar problemas, $66 \%$; quanto a formular alternativas de solução, 68\%; quanto a escolher uma solução $64 \%$.

Com relação ao desenvolvimento de habilidades e atitudes, assinalaram bom ou muito bom, quanto a trabalhar em equipe, $80 \%$; quanto a planejar, programar e controlar atividades, $86 \%$; quanto a comunicar-se escrita e oralmente, $74 \%$; quanto a criar alternativas e critérios para decisão, 84\%; quanto a preocupar-se com aspectos econômicos, sociais e ambientais, 95\%; quanto à capacidade de avaliação e postura ética neste processo, $95 \%$; quanto à capacidade de julgamento e negociação, $79 \%$.

Com relação ao entendimento sobre o trabalho em um projeto temático, assinalaram bom ou muito bom, quanto ao interesse do tema, 69\%; quanto à mudança no entendimento do assunto após a realização do trabalho, $80 \%$; quanto à compreensão do método de projeto de engenharia, $94 \%$. 
Com relação ao entendimento sobre a atuação do professor, assinalaram bom ou muito bom, no esclarecimento dos objetivos da disciplina, 94\%; na orientação em sala de aula, 83\%; quanto à avaliação do professor, $93 \%$.

Com relação ao entendimento sobre a forma de avaliação, assinalaram bom ou muito bom, quanto ao estímulo ao desenvolvimento de habilidades de trabalho em grupo e comunicação oral, $81 \%$; quanto ao favorecimento do aperfeiçoamento dos trabalhos realizados, $82 \%$; quanto à avaliação dos alunos pelos colegas, 50\%; quanto à competição entre grupos, $62 \%$.

Com relação ao entendimento sobre a disciplina, assinalaram bom ou muito bom, quanto à contribuição da disciplina para o entendimento sobre a forma de atuação de um engenheiro, $92 \%$; quanto à avaliação global sobre a disciplina, $80 \%$.

A resposta que teve a menor aprovação foi a que se referia à avaliação pelos colegas, o que pode ser explicado pelo paradigma da avaliação que mudou nesta disciplina. O processo de avaliação deixou de ser de exclusiva responsabilidade do professor que, antes, atribuía uma nota ao aluno, em função de provas ou projetos, que geralmente traduzia os acertos e erros observados e poderia não representar o que o aluno aprendeu. É conhecida a história do aluno que diz "eu tirei dez" ou "o professor me deu cinco" que traduz a dificuldade da autoavaliação.

\section{CONCLUSÃO}

Pode-se concluir que nessa atividade realizada pelos próprios alunos, num formato misto de aulas expositivas, pesquisas e trabalho em equipe, os alunos aprenderam fazendo. Com o apoio das aulas gravadas, de vídeos, de textos oficiais, mesmo com o ensino remoto, o desenvolvimento da disciplina atingiu seus objetivos, conforme aponta a enquete respondida pelos alunos.

A disciplina permitiu ao aluno desenvolver a habilidade de trabalhar em equipe, a capacidade de planejar, programar e controlar, a capacidade de se comunicar escrita e oralmente, a habilidade de criar alternativas e critérios para a decisão, a atitude de preocupação com aspectos econômicos, sociais e ambientais, a capacidade de avaliação e posicionamento ético nesse processo.

A disciplina pode ser visualizada em: edisciplinas.usp.br/course/view.php?id=73699

\section{REFERÊNCIAS}

ELMOR-FILHO, Gabriel et al. Uma Nova Sala de Aula é Possível: Aprendizagem Ativa na Educação em Engenharia. Rio de Janeiro: LTC, 2019. v. 1. 216p.

GIANNOTTI, Mariana A. et al Proposta de Aplicação de PBL nos Cursos de Engenharia. In: Congresso Brasileiro de Educação em Engenharia, 2008, São Paulo. Anais do XXXVI Congresso Brasileiro de Educação em Engenharia, 2008.

MASETTO, Marcos Tarcísio. Ensino de engenharia: técnicas para otimização das aulas. São Paulo: Avercamp, 2007.

NAKAO, Osvaldo S et al. Mapeamento de Competências dos Formandos da Escola Politécnica da USP. Revista de Ensino de Engenharia, v. 31, p. 31-39, 2012. 
NAKAO, Osvaldo S.; BRINATI, Hernani Luiz; GRIMONI, José Aquiles B. Acceptance of Innovative Technical of Teaching and Learning. In: ICEE: An International Conference on Engineering Education, 2011, Belfast. ICEE: An International Conference on Engineering Education. Anais. Belfast: ICEE, 2011.

SAVERY, John R.; DUFFY, Thomas. Problem based learning: An instructional mode and its constructivist framework. In: B. Wilson (ed.), constructivist learning environments: case studies in instructional design (p. 135-148). Englewood Cliffs, NJ: Educational Technology Publications, 1996.

TOLEDO, Bárbara. B.; et al. Avaliação da motivação de um aluno de engenharia/Evaluation of the motivation of the engineering student - Brazilian applied Science Review, v.3, n.4. 2019. Disponível em: http//www. brazilianjournals.com. Acesso em: 30 jul. 2020

\title{
AN ENGINEERING DISCIPLINE DURING THE 2020 PANDEMIC AND THE ENGINEERING CURRICULUM GUIDELINES OF 2019
}

\begin{abstract}
With the publication of the Engineering Curriculum Guidelines in 2019, the skills to be developed in undergraduate engineering students became very explicit. Through an engineering project proposed to students in the 1st semester, active learning was applied with great success in the subject of the course 0313101-Introduction to Civil Engineering at Escola Politécnica da USP. It is suitable to develop the knowledge, skills and attitudes pointed out according to the survey applied at the end of the semester, even with all the difficulties that occurred due to the social isolation imposed by the spread of the Corona virus.
\end{abstract}

Keywords: Curricular guidelines. Active learning. Introduction to Civil Engineering. Evaluation. 